\title{
Patient-reported outcome scores underestimate the impact of major complications in patients undergoing spine surgery for degenerative conditions
}

\author{
Borys V. Gvozdyev, MD, ${ }^{1}$ Leah Y. Carreon, MD, MSc, ${ }^{1}$ Christopher M. Graves, MD,1 \\ Stephanie A. Riley, BS, ${ }^{2}$ Katlyn E. McGraw, MPH, ${ }^{3}$ R. Joseph Head, MBS, ${ }^{1}$ John R. Dimar II, MD, ${ }^{1}$ \\ and Steven D. Glassman, MD'
}

${ }^{1}$ Norton Leatherman Spine Center, Louisville; ${ }^{2}$ University of Louisville School of Medicine; and ${ }^{3}$ University of Louisville School of Public Health and Information Sciences, Louisville, Kentucky

\begin{abstract}
OBJECTIVE Patient-reported outcomes (PROs) such as the Oswestry Disability Index (ODI) and EuroQol-5D (EQ-5D) are widely used to evaluate treatment outcomes following spine surgery for degenerative conditions. The goal of this study was to use the Charlson Comorbidity Index (CCMI) as a measure of general health status, for comparison with standard PROs.

METHODS The authors examined serial CCMI scores, complications, and PROs in 371 patients treated surgically for degenerative lumbar spine conditions who were enrolled in the Quality and Outcomes Database from a single center. The cohort included 152 males (41\%) with a mean age of 58.7 years. Patients with no, minor, or major complications were compared at baseline and at 1 year postoperatively.

RESULTS Minor complications were observed in 177 patients (48\%), and major complications in 34 (9\%). There were no significant differences in preoperative ODI, EQ-5D, or CCMI among the 3 groups. At 1 year, there was a significantly greater deterioration in CCMI in the major complication group (1.03) compared with the minor $(0.66)$ and no complication groups $(0.44, p<0.006)$, but no significant difference in ODI or EQ-5D.

CONCLUSIONS Despite equivalent improvements in PROs, patients with major complications actually had greater deterioration in their general health status, as evidenced by worse CCMI scores. Because CCMI is predictive of medical and surgical risk, patients who sustained a major complication now carry a greater likelihood of adverse outcomes with future interventions, including subsequent spine surgery. Although PRO scores are a key metric, they fail to adequately reflect the potential long-term impact of major perioperative complications.
\end{abstract}

https://thejns.org/doi/abs/10.3171/2017.3.SPINE161400

KEY WORDS lumbar fusion; complication; clinical outcomes; Charlson Comorbidity Index; Oswestry Disability Index; Quality Outcomes Database; QOD; degenerative

$\mathrm{P}$ ATIENT-REPORTED outcome (PRO) measures are widely used to evaluate treatment outcomes following spine surgery for degenerative conditions. Consistent with an expanding patient-centered approach to care, PROs have in many ways replaced traditional outcome measures such as complication rates, physician assessments, and subjective patient satisfaction. ${ }^{4}$ Two commonly used measures have demonstrated high validity combined with a reasonable response burden in evaluating patientreported outcomes following spine surgery. ${ }^{11}$ The Oswestry Disability Index (ODI) ${ }^{6,7}$ is a widely used assessment of postoperative improvement in pain and disability, whereas the EuroQol-5D (EQ-5D) ${ }^{5}$ is a validated assessment of overall health that is also relevant in economic analysis. ${ }^{11}$ Although these PRO scores reflect patients' perception of health status, the trend toward reliance on PROs to the exclusion of historical measures may be problematic. In FDA studies, success is typically defined by a combined metric including a given level of PRO improvement and the absence of significant complications. In contrast, success in most spine surgery publications is defined solely based on PRO improvement. In particular, the literature on lumbar

ABBREVIATIONS BMI = body mass index; CCMI = Charlson Comorbidity Index; DVT = deep venous thrombosis; EQ-5D = EuroQol-5D; $\mathrm{MI}=$ myocardial infarction; ODI = Oswestry Disability Index; PE = pulmonary embolus; $P R O=$ patient-reported outcome; $Q O D=$ Quality Outcomes Database; $Q O L=$ quality of life.

SUBMITTED December 1, 2016. ACCEPTED March 16, 2017.

INCLUDE WHEN CITING Published online July 28, 2017; DOI: 10.3171/2017.3.SPINE161400. 
TABLE 1. Frequency of complications in patients undergoing spine surgery for degenerative conditions

\begin{tabular}{lc}
\hline \multicolumn{1}{c}{ Complications } & Frequency \\
\hline Major & \\
\hline Wound infection, deep & 10 \\
\hline Stroke & 6 \\
\hline MI & 4 \\
\hline Pneumonia & 2 \\
\hline DVT & 5 \\
\hline PE & 3 \\
\hline Neurological deficit & 9 \\
\hline Other & 5 \\
\hline Minor & 7 \\
\hline Implant related & 21 \\
\hline Excessive bleeding & 10 \\
\hline Dural tear & 16 \\
\hline Wound drainage \&/or erythema & 5 \\
\hline Wound seroma & 6 \\
\hline Wound infection, superficial & 15 \\
\hline Mental confusion & 60 \\
\hline Radiculopathy & 14 \\
\hline Ileus & 4 \\
\hline Metabolic changes & 106 \\
\hline Anemia requiring transfusion & 4 \\
\hline Allergic reaction & \\
\hline
\end{tabular}

degenerative diseases raises concerns that standard PRO scores undervalue the impact of perioperative complications on long-term health. ${ }^{9}$

The Charlson Comorbidity Index (CCMI) ${ }^{3}$ was originally developed to predict 1-year mortality rates following medical hospital admissions. The CCMI has since been identified as a predictor of morbidity and mortality in patients following breast cancer, general surgery, and orthopedic surgery. $2,23,26$ The CCMI provides an objective assessment of health status, and increased baseline CCMI scores have been specifically associated with a greater incidence of hospital readmission following spine surgery. ${ }^{26}$ Because the CCMI is used to predict health-related outcomes in other arenas, it may be a useful tool in quantifying the deterioration in health status related to perioperative complications in spine surgery. The purpose of this study is to evaluate CCMI scores as a marker of potential deterioration in health status that may not be reflected by whether the patient "feels well," and therefore their status may not be captured by standard PRO quality of life (QOL) measures.

\section{Methods}

After we received institutional review board approval, patients from a single-center, multi-surgeon tertiary spine clinic registered in the Quality Outcomes Database (QOD) $)^{1,17,18}$ who had had a lumbar fusion with complete baseline and 12-month follow-up data by October 2015 were identified. The institutional review board waived the requirement for informed consent because this is an observational study; no intervention was planned, and the research involved minimal risk to the patients. As part of the QOD registry, the 3-level EQ-5D, ${ }^{5} \mathrm{ODI},{ }^{6,7}$ back pain scores $(0-10)$, and leg pain scores $(0-10)^{15}$ were determined prior to surgery, and at 3 and 12 months after surgery. In addition, medical records were reviewed to determine preoperative and 12-month postoperative CCMI scores and the occurrence of any perioperative complications. Perioperative complications were classified as minor or major based on Glassman et al. ${ }^{10}$

Subjects were then stratified into 3 groups: those who had a major complication, those who had a minor complication, and those who had no complications. One-way ANOVA was used to compare continuous variables, and Fisher's exact test was used to compare categorical variables among the 3 groups. All analysis was performed using IBM SPSS Statistics for Windows, version 21.0 (IBM Corp.). Threshold $\mathrm{p}$ value was set at $\mathrm{p}<0.01$ due to multiple concurrent analyses.

\section{Results}

Of 397 patients eligible for 12-month follow-up, 371 (93\%) patients had complete data and were included in the analysis. The cohort included 152 males (41\%) and 219 females $(59 \%)$. The mean age was $58.7 \pm 12.8$ years and the mean body mass index (BMI) was $31.0 \pm 6.3 \mathrm{~kg} / \mathrm{m}^{2}$ (mean $\pm \mathrm{SD}$ ). Minor complications were observed in 177 patients $(48 \%)$ and major complications in 34 patients (9\%). Deep wound infection was found in 10 patients, neurological deficit in 9, stroke in 6, myocardial infarction (MI) in 4, deep venous thrombosis (DVT) in 5, and pulmonary embolus (PE) in 3; these were the most commonly seen major complications. Postoperative anemia requiring transfusion $(n=106)$ and radiculopathy $(n=60)$ were the most common minor complications (Table 1).

Preoperatively, there were no significant differences in age, smoking history, BMI, or diagnosis among the 3 groups (Table 2). There was also no difference in baseline CCMI among the no complication, minor complication, and major complication groups (Table 3 ).

There was no significant difference in number of surgical levels, estimated blood loss, or surgical time. As expected, longer hospital stays were seen in patients with major complications, followed by those with minor and no complications, but this did not reach statistical significance (Table 4). Preoperative ODI and EQ-5D scores were sequentially worse in the minor and major complication groups, as compared with the no complication group. However, there was no baseline difference in back or leg pain scores between the groups.

At 1 year postoperatively, ODI and EQ-5D scores remained inferior in the major and minor complication groups, and this trend was also seen in leg pain scores (Table 5). However, although PROs in the major and minor complication groups remained worse compared with the no complication group, there were no significant differences in the change from baseline to 1 year postoperatively for ODI, EQ-5D, back pain, or leg pain scores. In contrast, at 1 year postoperatively, there was a significantly greater deterioration in CCMI in the major complication group 
TABLE 2. Summary of demographic and surgical data in patients undergoing spine surgery for degenerative conditions

\begin{tabular}{|c|c|c|c|c|c|}
\hline \multirow[b]{2}{*}{ Variable } & \multicolumn{4}{|c|}{ Complication Group } & \multirow{2}{*}{$\begin{array}{c}p \\
\text { Value }\end{array}$} \\
\hline & None & Minor & Major & Total & \\
\hline No. of patients & 160 & 177 & 34 & 371 & \\
\hline Male & 71 & 69 & 12 & 152 & 0.406 \\
\hline Smoker & 29 & 24 & 5 & 58 & 0.534 \\
\hline Mean age in yrs (SD) & $57.14(12.60)$ & $59.66(13.22)$ & $60.92(11.41)$ & $58.69(12.84)$ & 0.112 \\
\hline Mean BMI in $\mathrm{kg} / \mathrm{m}^{2}$ (SD) & $30.99(5.87)$ & $30.61(6.24)$ & $32.89(7.99)$ & $30.98(6.28)$ & 0.151 \\
\hline Diagnosis & & & & & 0.619 \\
\hline Disc herniation & 20 & 14 & 0 & 34 & \\
\hline Recurrent disc herniation & 8 & 6 & 2 & 16 & \\
\hline Spondylolisthesis & 67 & 78 & 18 & 163 & \\
\hline Stenosis & 28 & 35 & 7 & 70 & \\
\hline Adjacent-segment disease & 27 & 32 & 4 & 63 & \\
\hline Disc collapse & 10 & 12 & 3 & 25 & \\
\hline
\end{tabular}

(1.03) compared with the minor (0.66) or the no complication group $(0.44, \mathrm{p}=0.006)$ (Table 5).

\section{Discussion}

Patient-centered care, as applied to spine surgery, relies primarily on the application of PROs and shared decision making. Although this approach has gained traction, ${ }^{1,4,11}$, 13,14 its effectiveness depends on information that is accurate and can be readily conveyed to the patient. This is specifically relevant to patients undergoing spine surgery for degenerative conditions, who are faced with an important risk of perioperative complications. Multiple prior studies have identified risk factors that increase the likelihood of perioperative complications (such as advanced age, higher American Society of Anesthesiologists score, medical comorbidities, smoking, prolonged surgical time, increased blood loss, and poor bone quality). ${ }^{10,16,20,24,25}$ Particularly in more complex cases, multidisciplinary medical optimization, staging of prolonged procedures, and multimodality neuromonitoring have been used to reduce the risk of complications. ${ }^{8,12,27}$ In spite of the extensive work done to identify and minimize surgical complications, the impact of these events on PROs and long-term health has been incompletely characterized. ${ }^{10}$

Whereas the benefits of PRO are substantial, and have been widely discussed, ${ }^{1,4,11,13,14}$ the tendency to rely narrow- ly on patient perception may be problematic. The recent literature has raised concerns that standard PRO scores do not fully capture the impact of perioperative complications. ${ }^{9,10,19}$ As an example, regardless of PRO benefit, a postoperative PE might permanently alter the health profile of the patient. Although the patient may feel better, and report this improvement appropriately, the additional risk of anticoagulation therapy will not be reflected in those scores. In other words, the perception that the patient feels well is not the same as he or she actually being well. The dissociation of CCMI from improvement in standard PRO QOL scores as demonstrated in this study underlines the problem.

Minor complications were seen in nearly half (48\%) of the patients. However, the results of this and other studies suggest that the minor complications have a relatively limited impact on a patient's health at 1 year after surgery for degenerative lumbar spine conditions. ${ }^{9,22}$ In this study, there was no statistically significant difference seen in the outcomes between the groups with no complications and minor complications.

Major complications (9\%) were 5 times less likely to occur compared with minor complications. The length of hospital stay was longest in patients with major complications, trailed by those with minor complications and those who were complication free, although these differences did

TABLE 3. Summary of baseline PRO data in patients undergoing spine surgery for degenerative conditions

\begin{tabular}{lcccrcr}
\hline & \multicolumn{5}{c}{ Complication Group } & \multirow{2}{c}{$\begin{array}{c}\text { Total } \\
\text { Value }\end{array}$} \\
\cline { 2 - 5 } Variable & None & \multicolumn{1}{c}{ Minor } & Major & $29.96(8.35)$ & $26.72(7.81)$ & 0.002 \\
\hline ODI & $25.34(7.66)$ & $27.35(7.61)$ & $0.40(0.21)$ & $0.47(0.21)$ & 0.048 \\
\hline EQ-5D & $0.49(0.20)$ & $0.45(0.22)$ & $7.47(1.90)$ & $7.31(1.89)$ & 0.239 \\
\hline Back pain & $7.12(1.87)$ & $7.45(1.91)$ & $7.21(2.40)$ & $6.88(2.37)$ & 0.223 \\
\hline Leg pain & $6.64(2.49)$ & $7.03(2.25)$ & $3.79(2.29)$ & $3.83(2.44)$ & 0.523 \\
\hline CCMI & $3.68(2.48)$ & $3.98(2.43)$ & & &
\end{tabular}

Values are expressed as the mean (SD) unless otherwise specified. 
TABLE 4. Summary of surgical data in patients undergoing spine surgery for degenerative conditions

\begin{tabular}{|c|c|c|c|c|c|}
\hline \multirow[b]{2}{*}{ Variable } & \multicolumn{4}{|c|}{ Complication Group } & \multirow{2}{*}{$\begin{array}{c}p \\
\text { Value }\end{array}$} \\
\hline & None & Minor & Major & Total & \\
\hline No. of surgical levels & $1.35(0.59)$ & $1.45(0.63)$ & $1.44(0.56)$ & $1.14(0.61)$ & 0.352 \\
\hline Estimated blood loss (ml) & $416.07(325.00)$ & $481.95(375.56)$ & $464.15(282.39)$ & $451.84(347.15)$ & 0.218 \\
\hline Op time (mins) & $219.89(96.51)$ & $224.94(93.08)$ & $250.68(120.55)$ & $225.13(97.43)$ & 0.247 \\
\hline Length of stay (days) & $4.15(6.20)$ & $4.77(6.77)$ & $6.56(10.71)$ & $4.67(7.00)$ & 0.184 \\
\hline
\end{tabular}

Values are expressed as the mean (SD) unless otherwise specified.

not reach statistical significance. This finding is reasonably intuitive and consistent with existing literature. ${ }^{21,28} \mathrm{In}$ contrast, an explanation for the relationship between worse preoperative health-related QOL scores and subsequent complications is not inherently obvious. Worse general health might be reflected in the EQ-5D, but this is not duplicated in the preoperative CCMI scores. Worse EQ-5D and ODI scores both reflect greater disability, potentially impairing postoperative mobilization and rehabilitation.

More important, at 1 year postoperatively, there was a significantly greater deterioration in CCMI in the major complication group (1.03) compared with the minor (0.66) and complication-free groups $(0.44, \mathrm{p}=0.006)$. This deterioration in general health reflected by change in the CCMI score was not captured by either ODI or EQ-5D. There were no significant differences in the magnitude of ODI or EQ-5D improvement among the no complication, minor complication, and major complication groups at 1 year postoperatively. Whereas the ODI might not be expected to capture a change in general health, the EQ-5D is routinely viewed as a valid general health measure. ${ }^{5}$

Ideally, major complications might be considered differentially with regard to severity and duration of impact. Some major complications such as transient neurological deficit or DVT may resolve completely with appropriate treatment. On the other hand, a cerebrovascular accident or MI may have permanent effects on a patient's health. The symptoms related to an MI may be resolved by 1 year post-MI, but the patient's overall cardiovascular profile may have deteriorated. The CCMI is by definition effective in documenting the change in health status of a patient who has undergone spine surgery and then is affected by major complications. Other PROs such as ODI or EQ-5D may not reflect the above-mentioned decline in health, as evidenced by this study.

This study suggests the need for a more comprehensive spine-specific classification system of complications. The current WHO classification system that is commonly used to categorize major versus minor complications was designed for treatment of malignancy rather than spine surgery. ${ }^{18}$ The classification used in the present study does not stratify complications within the major or minor categories. ${ }^{10}$

Weaknesses of this study include the retrospective design, which increases the potential for bias. Furthermore, the study does not track the patient's experience between baseline and 1-year follow-up. One may speculate that patients with major complications underwent a more chal-

TABLE 5. Summary of PROs; follow-up data in patients undergoing spine surgery for degenerative conditions

\begin{tabular}{|c|c|c|c|c|c|}
\hline \multirow[b]{2}{*}{ Follow-Up Data } & \multicolumn{4}{|c|}{ Complication Group } & \multirow{2}{*}{$\begin{array}{c}p \\
\text { Value }\end{array}$} \\
\hline & None & Minor & Major & Total & \\
\hline \multicolumn{6}{|l|}{ ODI } \\
\hline 12-month score & $16.31(10.55)$ & $19.80(10.71)$ & $21.10(10.74)$ & $18.41(10.78)$ & 0.004 \\
\hline 12-month change & $9.03(7.98)$ & $7.55(8.68)$ & $8.86(10.58)$ & $8.31(8.59)$ & 0.268 \\
\hline \multicolumn{6}{|l|}{$E Q-5 D$} \\
\hline 12-month score & $0.69(0.24)$ & $0.62(0.24)$ & $0.56(0.22)$ & $0.65(0.24)$ & 0.006 \\
\hline 12-month change & $0.20(0.23)$ & $0.17(0.24)$ & $0.16(0.24)$ & $0.18(0.24)$ & 0.563 \\
\hline \multicolumn{6}{|l|}{ Back pain } \\
\hline 12-month score & $4.23(2.84)$ & $4.90(2.79)$ & $5.44(3.28)$ & $4.66(2.88)$ & 0.026 \\
\hline 12-month change & $2.89(2.84)$ & $2.55(2.77)$ & $2.03(3.34)$ & $2.65(2.86)$ & 0.235 \\
\hline \multicolumn{6}{|l|}{ Leg pain } \\
\hline 12-month score & $3.30(3.14)$ & $4.02(3.10)$ & $5.00(3.57)$ & $3.80(3.19)$ & 0.008 \\
\hline 12-month change & $3.34(3.49)$ & $3.01(3.14)$ & $2.21(3.43)$ & $3.08(3.33)$ & 0.185 \\
\hline \multicolumn{6}{|l|}{ CCMI } \\
\hline 12-month score & $4.11(2.75)$ & $4.63(2.80)$ & $4.82(2.77)$ & $4.43(2.78)$ & 0.157 \\
\hline 12-month change & $0.44(0.86)$ & $0.66(1.10)$ & $1.03(1.36)$ & $0.60(1.04)$ & 0.006 \\
\hline
\end{tabular}

Values are expressed as the mean (SD) unless otherwise specified. 
lenging acute recovery process, such that the actual impact may be underappreciated due to insufficient recall at 1-year follow-up.

Despite these shortcomings, the results of the study place in question the ability of ODI and EQ-5D to reflect the deterioration in a patient's underlying health profile after surgery for degenerative lumbar spine conditions. The current emphasis on PROs misses the distinction between feeling well and being well, which is highlighted by CCMI deterioration after major complications. It is reasonable to better educate patients on the differences in overall health impact between minor and major complications. Although the minor complications are fairly common, the health impact appears to be self-limited. On the other hand, it is imperative that patients undergoing spine surgery understand the potential health impact caused by major complications prior to the intervention. Moreover, it must be emphasized that the impact of some major complications may be permanent.

\section{Conclusions}

Patient-centered care emphasizes outcome measures based on QOL. The ODI and EQ-5D have been established as primary instruments for assessing patient-centered outcomes following lumbar spine surgery. When stratified by perioperative complications, these traditional PRO measures failed to adequately reflect the overall deterioration in health status related to major complications, as evidenced by the CCMI. Increased CCMI scores have been associated with higher morbidity and mortality in many different patient populations, and are reflective of medical and surgical risk. Patients who sustained a major complication following spine surgery demonstrated increased CCMI scores and thus carry a greater likelihood of adverse outcomes, with future interventions including subsequent spine surgery. Although PRO scores are a key metric, they may fail to reflect the potential long-term impact of major perioperative complications.

\section{References}

1. Asher AL, Speroff T, Dittus RS, Parker SL, Davies JM, Selden N, et al: The National Neurosurgery Quality and Outcomes Database ( $\left.{ }^{2} \mathrm{QOD}\right)$ : a collaborative North American outcomes registry to advance value-based spine care. Spine (Phila Pa 1976) 39 (22 Suppl 1):S106-S116, 2014

2. Braithwaite D, Moore DH, Satariano WA, Kwan ML, Hiatt RA, Kroenke C, et al: Prognostic impact of comorbidity among long-term breast cancer survivors: results from the LACE study. Cancer Epidemiol Biomarkers Prev 21:11151125,2012

3. Charlson ME, Pompei P, Ales KL, MacKenzie CR: A new method of classifying prognostic comorbidity in longitudinal studies: development and validation. J Chronic Dis 40:373383, 1987

4. DeVine J, Norvell DC, Ecker E, Fourney DR, Vaccaro A, Wang J, et al: Evaluating the correlation and responsiveness of patient-reported pain with function and quality-of-life outcomes after spine surgery. Spine (Phila Pa 1976) 36 (21 Suppl):S69-S74, 2011

5. EuroQol Group: EuroQol-a new facility for the measurement of health-related quality of life. Health Policy 16:199208, 1999
6. Fairbank JC, Couper J, Davies JB, O'Brien JP: The Oswestry low back pain disability questionnaire. Physiotherapy 66:271-273, 1980

7. Fairbank JC, Pynsent PB: The Oswestry Disability Index. Spine (Phila Pa 1976) 25:2940-2952, 2000

8. Fitz-Henry J: The ASA classification and peri-operative risk. Ann R Coll Surg Engl 93:185-187, 2011

9. Glassman SD, Carreon LY, Dimar JR, Campbell MJ, Puno RM, Johnson JR: Clinical outcomes in older patients after posterolateral lumbar fusion. Spine J 7:547-551, 2007

10. Glassman SD, Hamill CL, Bridwell KH, Schwab FJ, Dimar JR, Lowe TG: The impact of perioperative complications on clinical outcome in adult deformity surgery. Spine (Phila Pa 1976) 32:2764-2770, 2007

11. Godil SS, Parker SL, Zuckerman SL, Mendenhall SK, Glassman SD, McGirt MJ: Accurately measuring the quality and effectiveness of lumbar surgery in registry efforts: determining the most valid and responsive instruments. Spine J 14:2885-2891, 2014

12. Lall RR, Lall RR, Hauptman JS, Munoz C, Cybulski GR, Koski T, et al: Intraoperative neurophysiological monitoring in spine surgery: indications, efficacy, and role of the preoperative checklist. Neurosurg Focus 33(5):E10, 2012

13. Lurie JD, Berven SH, Gibson-Chambers J, Tosteson T, Tosteson A, Hu SS, et al: Patient preferences and expectations for care: determinants in patients with lumbar intervertebral disc herniation. Spine (Phila Pa 1976) 33:2663-2668, 2008

14. Lurie JD, Spratt KF, Blood EA, Tosteson TD, Tosteson AN, Weinstein JN: Effects of viewing an evidence-based video decision aid on patients' treatment preferences for spine surgery. Spine (Phila Pa 1976) 36:1501-1504, 2011

15. McCaffery M, Beebe A: Pain: Clinical Manual for Nursing Practice. Baltimore: Mosby, 1993

16. McDonnell MF, Glassman SD, Dimar JR II, Puno RM, Johnson JR: Perioperative complications of anterior procedures on the spine. J Bone Joint Surg Am 78:839-847, 1996

17. McGirt MJ, Parker SL, Asher AL, Norvell D, Sherry N, Devin CJ: Role of prospective registries in defining the value and effectiveness of spine care. Spine (Phila Pa 1976) 39 (22 Suppl 1):S117-S128, 2014

18. McGirt MJ, Speroff T, Dittus RS, Harrell FE Jr, Asher AL: The National Neurosurgery Quality and Outcomes Database $\left(\mathrm{N}^{2} \mathrm{QOD}\right)$ : general overview and pilot-year project description. Neurosurg Focus 34(1):E6, 2013

19. Mirza SK, Deyo RA, Heagerty PJ, Turner JA, Lee LA, Goodkin R: Towards standardized measurement of adverse events in spine surgery: conceptual model and pilot evaluation. BMC Musculoskelet Disord 7:53, 2006

20. Rao SB, Vasquez G, Harrop J, Maltenfort M, Stein N, Kaliyadan $\mathrm{G}$, et al: Risk factors for surgical site infections following spinal fusion procedures: a case-control study. Clin Infect Dis 53:686-692, 2011

21. Sanoufa M, Smisson W, Floyd H, Robinson JS: The effect of anaemia on hospital length of stay in lumbar decompression and fusion procedures. J Perioper Pract 25:267-271, 2015

22. Shaffer WO, Baisden JL, Fernand R, Matz PG: An evidencebased clinical guideline for antibiotic prophylaxis in spine surgery. Spine J 13:1387-1392, 2013

23. St-Louis E, Iqbal S, Feldman LS, Sudarshan M, Deckelbaum DL, Razek TS, et al: Using the age-adjusted Charlson comorbidity index to predict outcomes in emergency general surgery. J Trauma Acute Care Surg 78:318-323, 2015

24. Tang H, Zhu J, Ji F, Wang S, Xie Y, Fei H: Risk factors for postoperative complication after spinal fusion and instrumentation in degenerative lumbar scoliosis patients. J Orthop Surg 9:15, 2014

25. Veeravagu A, Patil CG, Lad SP, Boakye M: Risk factors for postoperative spinal wound infections after spinal decompression and fusion surgeries. Spine (Phila Pa 1976) 34:1869-1872, 2009 
26. Voskuijl T, Hageman M, Ring D: Higher Charlson Comorbidity Index scores are associated with readmission after orthopaedic surgery. Clin Orthop Relat Res 472:1638-1644, 2014

27. Whitmore RG, Stephen JH, Vernick C, Campbell PG, Yadla S, Ghobrial GM, et al: ASA grade and Charlson Comorbidity Index of spinal surgery patients: correlation with complications and societal costs. Spine J 14:31-38, 2014

28. Zheng F, Cammisa FP Jr, Sandhu HS, Girardi FP, Khan SN: Factors predicting hospital stay, operative time, blood loss, and transfusion in patients undergoing revision posterior lumbar spine decompression, fusion, and segmental instrumentation. Spine (Phila Pa 1976) 27:818-824, 2002

\section{Disclosures}

Dr. Carreon is an employee of Norton Healthcare and a consultant for AOSpine and Washington University at St. Louis. She has received funds for travel from the University of Southern Denmark and the University of Louisville. Support of a nonstudy-related clinical or research effort overseen by Dr. Carreon was received from the Orthopaedic Research and Education Foundation (OREF), Norton Healthcare, Scoliosis Research Society (SRS), Pfizer, Integra, and IntelliRod. She is a member of the Editorial Advisory Boards for Spine, The Spine Journal, and Spine Deformity; of the University of Louisville Institutional Review Board; and of the Research Committee for SRS. NuVasive provided funds directly to the database company. No funds are paid directly to the individual or their institution (June 2012April 2015). Dr. Dimar is a patent holder with and a consultant for Medtronic. Dr. Glassman is an employee of Norton Healthcare, and consults for, holds a patent with, and receives royalties from Medtronic. He also states that NuVasive provided funds directly to the database company-no funds were paid directly to him or his institution; and he is a past president of the Scoliosis Research Society.

\section{Author Contributions}

Conception and design: Gvozdyev, Glassman. Acquisition of data: all authors. Analysis and interpretation of data: Carreon. Drafting the article: Gvozdyev. Critically revising the article: all authors. Reviewed submitted version of manuscript: Carreon, Graves, Riley, McGraw, Head, Dimar, Glassman. Approved the final version of the manuscript on behalf of all authors: Carreon. Statistical analysis: Carreon. Administrative/technical/material support: McGraw, Head.

\section{Correspondence}

Leah Y. Carreon, Norton Leatherman Spine Center, 210 E Gray St., Ste. 900, Louisville, Kentucky 40202. email: leah.carreon@ nortonhealthcare.org. 